\title{
DECISION TREE APPROACH FOR PLANTS STOPPAGE DECISION PROCESS DUE TO POWER LIMITATION CASE STUDY: STEEL COMPANY
}

\author{
Mohamed Saied Essa Othman Hussien \\ Level2 Automation Flat Steel Department, EZDK for iron and steel Co., Alexandria, Egypt \\ Email:msaied@ezzsteel.com.eg
}

\begin{abstract}
This paper presents an approach to the design and construction of an innovative decision support system to help the top management of multi plants companies to take the optimum decision in case of power limitation to choose which plant or plants will be stopped with minimum losses. A case study is also presented for a steel company, it contains a technical study for applying the DSS concepts. This case study can be considered as a model for any multi plants company either in steel industries or else, which faces the same problem and needs a DSS to take the optimum decision. It describes the system in terms of the nature of the decision problem, discusses factors which affect the problem and considers the design goals.
\end{abstract}

Keywords: Decision support systems, DSS design, Decision tree, Information systems, Power limitation, Iron and steel industry.

\section{INTRODUCTION}

Over the past few years Egypt has witnessed an increase in the consumption of electricity, which leads the generation stations to ask the big companies to reduce their power consumption during the high load intervals in order to maintain the frequency value within tolerance.The decision of reducing the power consumption in large companies isn't easy. It needs many studies, scheduling and meetings to decide which plant or plants can be stopped with the minimum effect on the productivity and the availability of the company. This research proposes a methodology and a case study of a DSS capable of identifying the best alternatives of stopping plants under certain circumstances as will be explained. We start by giving an overview of some basic definitions as a theoretical background in section 1 and by providing some pointers to related work in section 3. Then we explain problem definition, motivation and the estimated benefits from using such system during Sections 4, 5, and 6 respectively. Section 7 presents the proposed design methodology which is illustrated through a case study of a steel company in section 8 . Finally, we conclude the paper and discuss the possible future work.

\section{THEORITICAL BACKGROUND}

\subsection{DECISION SUPPORT SYSTEM, DSS}

There are several definitions for DSS but only one will be adopted which defines it as an interactive computer based system that intended to help decision makers using communications technologies, data, documents, knowledge and models to 
complete decision process tasks [2]. It is intended to help decision makers to compile useful information from raw data, documents, personal knowledge, and/or business models to identify and solve problems and make decisions [2]. DSS helps decision takers to decide with a clear vision. The DSS development studies conducted during the last 15 years $[14,15]$ have identified more than 30 different approaches to the design and construction of decision support methods and systems [3]. None of these approaches predominate. DSS development processes remain very distinct and project-specific.

\subsection{DECISION TREE}

A decision tree (DT) is "a graphical presentation of expected value calculation" [8], it is "an attempt to explicitly determine the available alternatives, the expected costs, payoffs and probability of success associated with each alternative" [16]. It is considered one of the most easy to use tools in decision analysis [6]. DT offers simple, readily understandable procedures for diagnosing specific problem.

\subsection{GOAL-SEEKING ANALYSIS (BACK-SOLVING)}

In computing, it defines as the ability to calculate backward to obtain an input that would result in a given output.

\subsection{WHAT-IF ANALYSIS}

Stefano Rizzi defined the What-if analysis as a data intensive simulation whose goal is to inspect the behaviour of a complex system. In particular, what-if analysis measures how changes in a set of independent variables impact a set of dependent variables.

\subsection{SENSITIVITY ANALYSIS}

It is a study of how the variation in the output of a model can be apportioned, qualitatively or quantitatively, to different sources of variation.

\section{LITERATURE REVIEW}

There are many applications that use DT either in an industrial field or in an academic field. In this section we will mention some of them just to focus on the importance of DSSDT in different fields. Claire Cardie used DT to improve the performance of the Case based learning (CBL) systems. By creating an attribute weight vector for each concept where the weights are either 0 or 1 . He indicates that decision tree algorithms can be used to improve the performance of some $\mathrm{CBL}$ systems without relying on potentially expensive expert knowledge [13]. Moussa, Ruwanpura and Jergeas introduced an application to DT's by using a Special Purpose Simulation program. The DSS-DT module accepts constant and density distribution values and integ-rates with other modules in the DSS template [6].

Salzberg's present an approach that uses a decision tree classifier as the primary algorithm in order to distinguish between coding and noncoding DNA for sequences as short as 54 base pairs [13]. A hierarchical computational structure to recognize emotions is proposed in [1] to map an input speech noise into one of the multiple emotion classes through subsequent layers of binary classifications. DT is used to solve the easiest classification tasks first which allows mitigating error propagation. From the previous cases, it's clear that DT algorithm is commonly used for classification in different fields.

\section{PROBLEM DIAGNOSIS}

Power systems have to be operated in a stable manner and the power system frequency has to fulfil tolerance criteria. However, when the load increases on the electrical network and because the frequency is inversely proportional to the load, it falls below the 
allowed limits, which causes a trip for the entire generation station.

JügrenSchlabbach and Karl- Heinz Rofalski give an example in [4] which states that if a drop in the frequency, cannot be avoided by load frequency control or if the frequency remains below vertain limit values for a longer time during transition periods, then load shedding by frequency relays has to be applied. In the UCTE system with nominal frequency $50 \mathrm{~Hz}$ the agreed grading plan is:

1. Frequency drops to $49.8 \mathrm{~Hz}$ : activation of reserves according to a coordinated plan

2. Frequency drops to $49.0 \mathrm{~Hz}$ : instantaneous disconnection of $10-15 \%$ of the power system load

3. Frequency drops to $48.7 \mathrm{~Hz}$ : instantaneous disconnection of a further $10-15 \%$ of the power system load

4. Frequency drops to $48.4 \mathrm{~Hz}$ : third load - shedding stage, a further $15-20 \%$ of the power system load to be switched off

5. Frequency drops to $47.5 \mathrm{~Hz}$ : power stations to disconnect from the power system immediately

Therefore, the station has to decrease its load by putting some loads out of service. On the scope of industry, cutting the power may cause disasters. Consequently, the electricity generation station must tell the industrial companies about the expected time of spikes loads and determine the maximum power limitation which is allowed for the company.

With the power limitation, it is possible to prevent peaks in the power consumption of the heating or limitation of the complete current consumption.

The top management (TM) of the company should compromise between the criticality of its plants. They have to determine which plant to stop and which plant to run, in addition to justifying their decision.

\section{MOTIVATION}

The project is principally motivated by the recurrence of the problem due to the shortage in electrical power in Egypt nowadays. Egypt's generating capacity at the end of 2013 was 27 gigawatts (GW), slightly higher than the daily peak demand of $24 \mathrm{GW}$, according to MEES. Egypt struggles with natural gas shortages, particularly during the summer months and typically imports fuel oil and diesel to cover the shortage. Rising power demand, natural gas supply shortages, an aging infrastructure, and an inadequate generation and transmission capacity have led to frequent blackouts in Egypt.

Decision maker faces difficulties as data obtained are from different sources. Some of those data aren't integrated to others while others are collected manually. A lot of time and effort is lost between processing the data collected and presenting the findings to the TM to take a suitable decision.

The problem by its nature is a semi structured problem, which enables us to use DSS. Under the large amount of required changing information that keeps changing and the complexity of the options, the manual system will not lead to take the optimum decision; hence there is a need to develop DSS because the right decision today is not necessarily the right decision tomorrow.

\section{BENEFITS OF USING PLDSS}

The System is designed to support managerial decision making in solving the following problems:

a) Decision quality

By determining all alternatives and their weights, TM will be able to take the optimum decision which is appropriate for each situation. 
b) Cost reduction

The optimum decision leads to reducing the cost of stoppage by eliminating its time and saving the workers time in production.

c) Increase productivity

The use of system leads to minimize the downtime and increase the productivity.

d) Time savings

The system helps TM to reduce their meetings to discuss the situation and to get the decision making data from concerned sections

e) Green system

The system is paperless. Therefore, it reduces the amount of paper and ink and helps to protect our environment.

\section{DESIGN STEPS FOR A PLDSS}

We propose a typical series of design steps to design such system as the following:

Step 1: Define the environment of the company

Step 2: Determine the main objectives for the system

Step 3: Identify all effecting factors

Step 4: Determine the decision analysis process

Step 5: Design the suitable DT based on the predefined effecting factors

Step 6: Design the system's flowchart

Step 7: List the existing system data base engines

Step 8: Choose Deployment Strategy

All of these steps will be explained in details through the case study.

\section{ILLUSTRATIVE CASE STUDY: STEEL COMPANY}

As an illustrative case study, the following section maps the proposed design methodology with a steel company step by step starting from comprehension of the company environment till system design.

\subsection{STEEL COMPANY ENVIRONMENT}

The company used in this case is a leading steel producer in the Middle East, with a growing presence in markets around the world. The company's overall capacity is 5.8 million tons per year, including 3.5 million tons of long products and one million tons of hot rolled coil (HRC), plus 1.3 million tons of flexible capacity (long products or HRC).

The company as shown in Figure 1 consists of the following plants:

a) Three direct reduction plants (DRP) from Midrex Technologies Inc. with a combined output of around 3 million tons/year; this equipment converts iron ore into iron metal with low levels of residual elements.

b) Steel Making plants which produce the molten steel by four ultra-highpower Electric Arc Furnaces (EAF), each with a capacity of 80 tons. These furnaces run with continuous charging of direct reduced iron (DRI). The molten steel is next transferred to the ladle furnaces using a technique designed to reduce slag carry over.

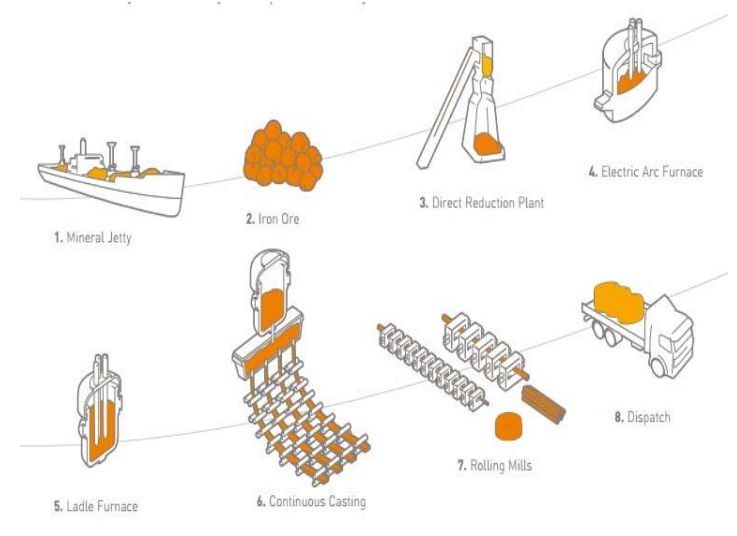

Fig.1. Case study Steel Company 
Then, the steel is cast into billets in multistrand continuous casting machines. Billets from the casters pass directly into one of the company's long-product multistand rolling mills, producing either bar or rod. The billets are reheated in a furnace before being rolled into rods or bars.

c) The flat steel plant which produces the molten steel by one ultra-highpower EAF with a capacity of 160 tons. This furnace runs with continuous charging of direct reduced iron (DRI). The molten steel is next transferred to the ladle furnaces. The plant houses the Compact Strip Production (CSP) technology producing strip that consist of the thin slab caster to cast into slabs in continuous casting manner and multi-stand hot rolling mills which roll the slabs from the caster directly into HRC.

The plant produces one million tonnes of HRC per year with thickness from $1.2 \mathrm{~mm}$ to $12.7 \mathrm{~mm}$ and widths from $800 \mathrm{~mm}$ to 1,500 $\mathrm{mm}$.

\subsection{Design MaIn ObJeCtives}

The major objective of this study is to build a DSS in order to:

1. Supply TM of the steel Company with all possible alternatives to help them in taking the optimum decision in order to achieve the power limitation.

2. Study the expected shut down due to power limitation

\subsection{EFFECTING FACTORS}

Basically, to enable the TM to take the optimum decision, they should be informed with the necessary abstracted information which is the most important role of the system. To provide such information, the analysis has to include all probable factors; So many meetings and surveys are held to determine the effecting factors for this steel company. The following factors are determined:

1. Production plan for each plant.

2. Actual Consumed power for each plant.

3. Planned Consumed power for each plant.

4. Scheduled repair days.

5. Current stock for each plant.

6. DRI Metallization.

7. DRI Carbon.

8. Currency Exchange ratio.

9. Target Power Limitation.

A brief for each effecting factor will be explained in the remaining part of this section:

\section{Production plan for each plant}

Production plan is one of the main tasks which are executed by the planning and control department. They prepared four types of plans as follows:

a) Annual production plan

It explains the plants planned activities during the next year (from Jan. till end of Dec.). It is usually issued in Nov. of the previous year (Figure 2).

b) Semi Annual production plan

It explains the plants planned activities in the second half of the year (from Jul. till end of Dec.) in addition to the actual results for the first half of the year.

c) Monthly production plan

It explains the plants planned activities during a month. Its figures should match the annual plan. It depends on sales expectation for this month considering the planned shut-down schedule (Figure 3). 


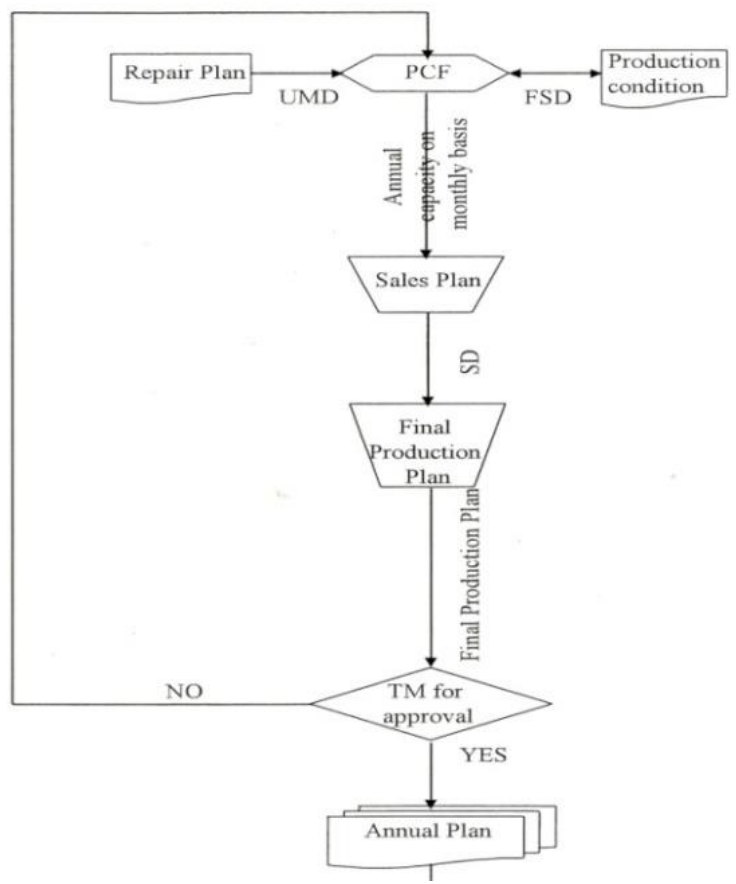

Fig.2. Annual Production Plan
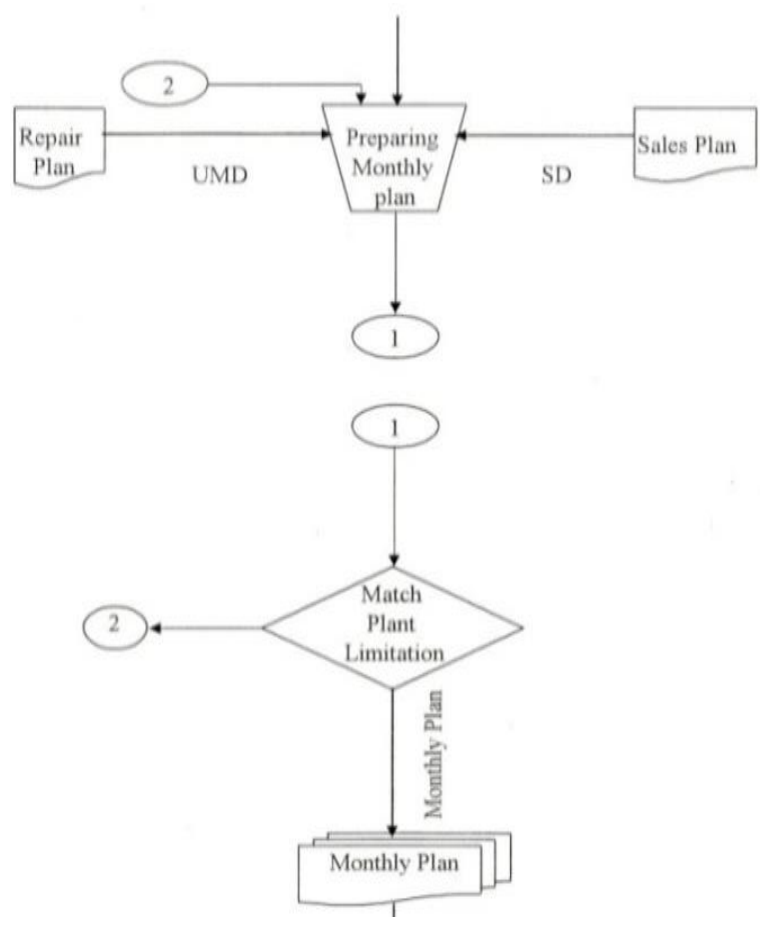

Fig.3. Monthly Production Plan

d) Weekly production plan

It explains the plants planned activities during a week. It deals with actual contracted quantity and considers the priorities which are aiming to keep smooth running for all plants (Figure 4).

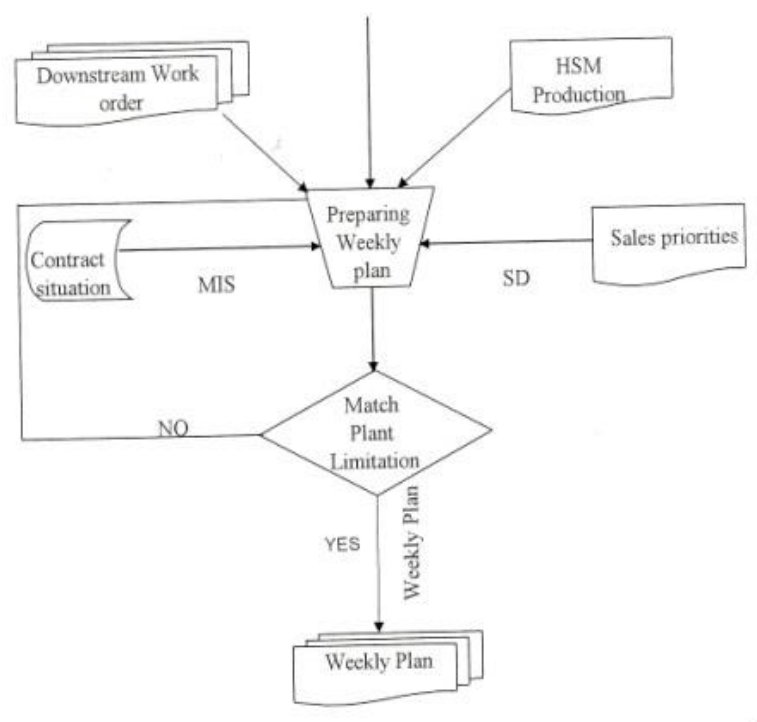

Fig.4. Weekly Production Plan

\section{Scheduled repair and shutdown days}

There is a repair schedule for each plant which is planned by the maintenance planning and control subsection in each plant

\section{Net profit of products}

The net profit for the product means its market price for this product which depends on its order type either for export or for the local market (affected by currency exchange ratio). The expected income for the company is calculated by multiplying the planned sales quantity by the estimated sales prices.

\section{Required Power Limitation}

The system must feed with the required amount of power limit which the electricity generation company asks to maintain $n$ each situation or by an estimated limit in case of planning just for the observation of estimated decisions and for study purposes.

\section{Consumed Power For Each Plant}

Each plant needs a certain amount of electrical power to work. We will focus on three plants DRP, SMP1 and FSP as the dominant plants in consumed power. 


\section{Stock}

Each plant has its own stock based on its product. We will focus on three types of stock:

a) DRI

Direct reduction iron (DRI) is the product of direct reduction plant (DR) which is used as an input material for other plants' furnaces.

b) Billets

Billet is the product of steel making plant no.1 (SMP1) which can be sold or rolled to produce the rebar or wire products. The billets stock is stored on a billet yard.

c) Coils

Coil is the product of flat steel plant (FSP). The coils stock is stored on coil yard.

\section{DRI quality}

Referring to [3], The DRI quality affects electric energy consumption. When talking about the influence of DRI quality on electric Energy consumption, we will focus on the metallization and carbon concentration in DRI.
a) Effect of Metallization on electric energy consumption:

The metallization degree of DRI is defined as the percentage of iron oxide reduced to metallic iron thus:

Met\% $=($ Metallic Fe \% / Total Fe \%) x 100

Where: Total $\mathrm{Fe}=$ Metallic $\mathrm{Fe}+\mathrm{Fe}$ in Iron Oxide

By plotting a graph between the actual results of EAF electric energy consumption and DRI metallization at the same EAF availability taking into consideration that during study period, DRI carbon was $1.8 \%$ and DRI ratio was $85 \%$. It is found that the average increase in EAF electric Energy consumption due to decreasing 1\% DRI metallization is about 12 KWH/TMS as shown in Figure 5. b) Effect of Carbon percentage on electric energy consumption

By decreasing 1\% DRI carbon, Energy consumption will increase by $32 \mathrm{KWH} / \mathrm{TMS}$ [2].

For example: a drop of $0.3 \%$ in DRI carbon percentage can be effect on the electrical energy consumption by $3.6 \mathrm{KWH} / \mathrm{TMS}$.

\subsection{Decision Analysis Process}

In the proposed model, there are many parameters which need different types of analysis. The used analysis processes are as follows:

a) Goal-seeking analysis

For this problem, the main objective is to set all possible alternatives for stopping plants in order to achieve the required power limit.

The user must feed the program with the required amount of power limitation. As a result, the system estimates all alternatives due to saved power by calculating different combinations of the FSD plants, DRD plants required power (DRD1, DRD2, and DRD3) and SMP1 plants (SMP11, SMP12, SMP13, and SMP14) in order to achieve the required power limitation.

b) What-if analysis

It can be used with the stock and production plan (export and import) and the schedule shutdown days to determine the effect of each of them on the decision.

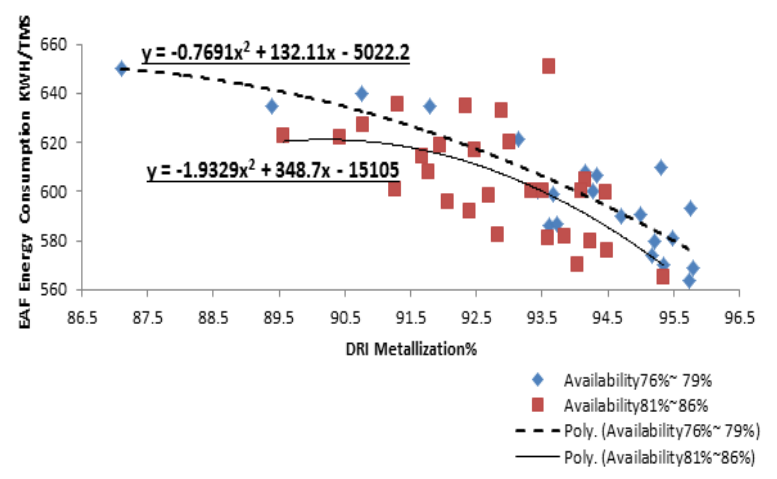

Fig.5. Energy consumption vs. Metallization 
c) Sensitivity analysis

The sensitivity analysis can be used to study relation of the stock amount and type and exchange ratio and their effect on the decision.

\subsection{SYSTEM FLOW CHART}

Flow chart is a good tool for stating the general system flow. For the case study system the flow chart is as shown in Figure 6. First of all it loads all required data which represent the effecting factors, then it generates all possible alternatives through a goal seeking analysis as explained earlier. Those alternatives will take weights based on the current stock, type of customer and the scheduled stoppage.

\subsection{DECISION TREE}

The most important step is to determine the DT of your system. In this case study company, the DT is as shown in Figure 7.

Then they are filtered with respect to their weights to choose the alternatives with the highest weights which represent the best alternatives that TM will choose from.

\subsection{EXISTING DATa SOURCES}

The system may collect data from different data sources and different platforms. In this case study company, there are many database management systems (DBMS). The system needs several data as we explained earlier. This data is scattered between different DBMSs, so all DBMSs will act as inputs for the system as shown in Figure 8.

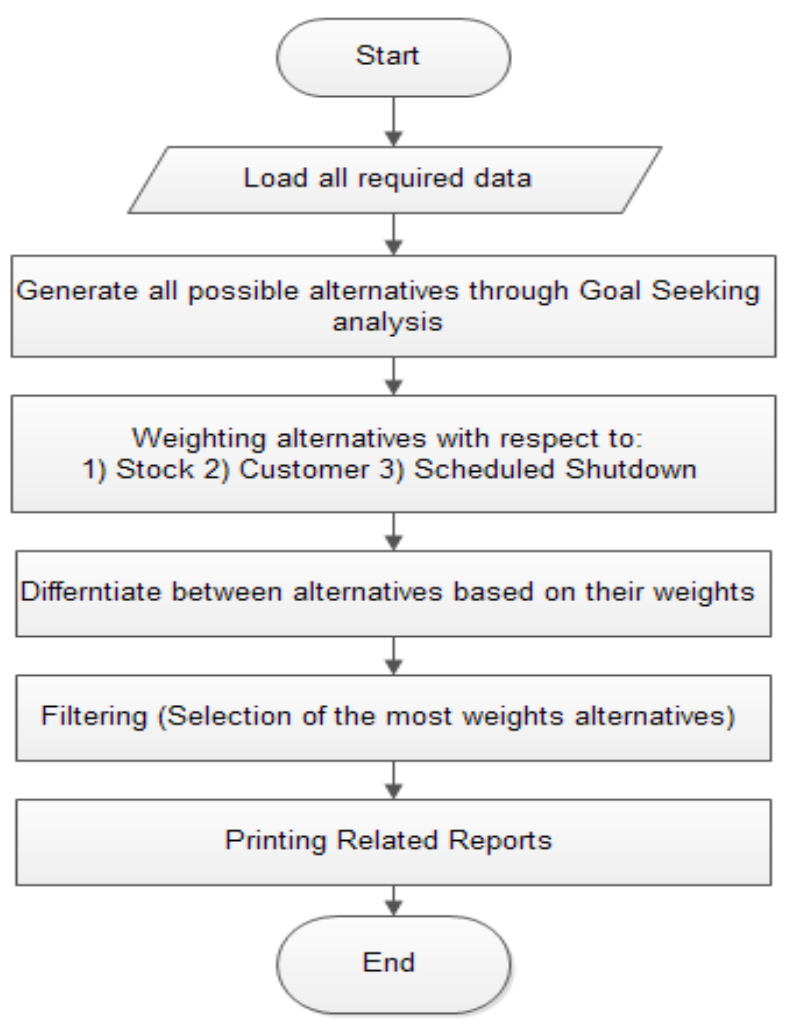

Fig.6. System Flow chart

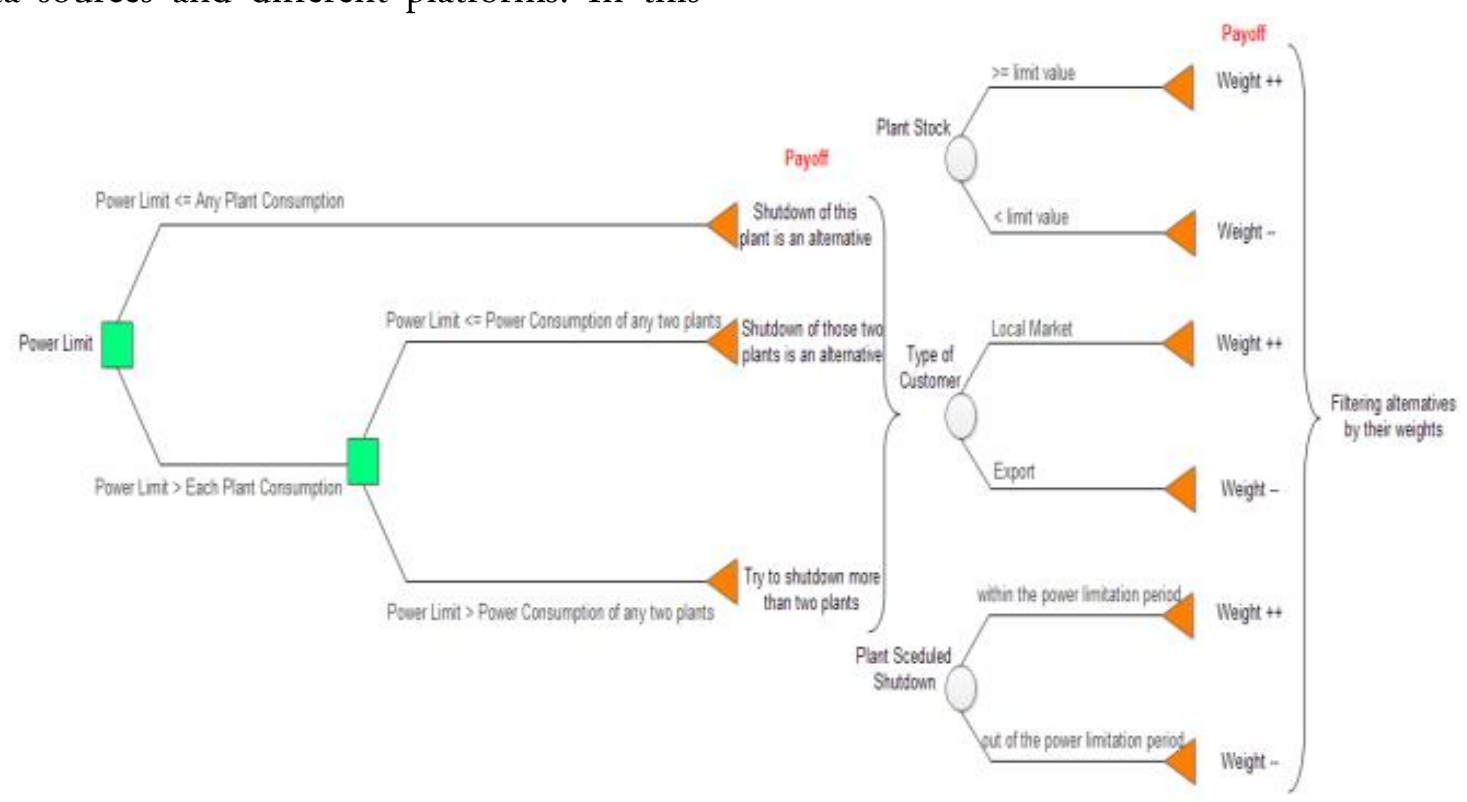

Fig.7. DT for Case Study Steel Company 


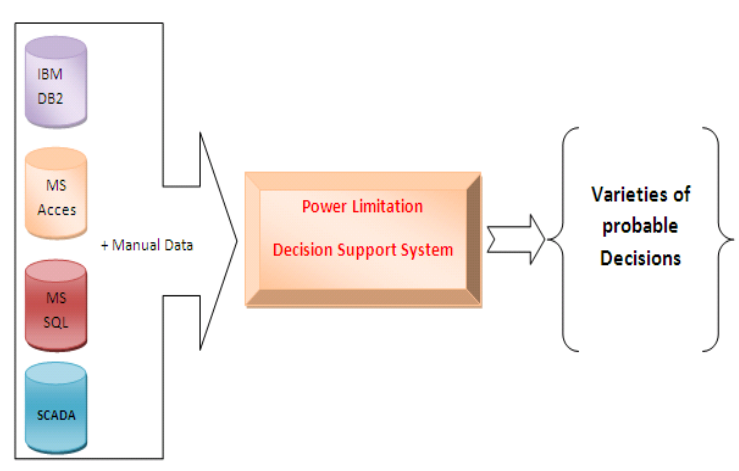

Fig.8. Several Sources of data

\section{CONCLUSION}

The main contribution of this research is in specifying a methodology for designing a DSS for power limitation in a multi plant based on DT algorithm. Such system will support TM with the best alternatives to choose the best decision depending on the effecting factors at the time of decision. It will be also highly useful in saving time and effort.

For the proof of concept, an empirical study is presented for a steel company showing the design procedures mapped to our proposed methodology, and for IGSR supervision by Dr. Ahmed El Fatatry.

\section{ACKNOWLEDGMENT}

The Author would like to express his gratitude to his management in EZDK Co. for providing him with support and be pleased to thank EZDK staff especially Eng. Tamer Aref for his effort and cooperation.

\section{REFERENCES}

[1] Chi-Chun Leea, Emily Mowera, Carlos Bussob, SungbokLeea, ShrikanthNarayanana, "Emotion Recognition using a Hierarchical Binary Decision Tree approach”, 2011.

[2] MARIN Georgiana, "Decision support systems", Journal of Information Systems \& Operations Management, 2008, vol. 2, issue 2, pp. 513-520.

[3] Hradec and Moravici, "Metal", 2007.

[4] JügrenSchlabbach and Karl- Heinz Rofalski, "Power System Engineering. Planning, design and operation of power systems and Equipment", 2007.

[5] Leonard L. Grigsby, "Electric Power Generation, Transmission and Distribution", Second edition, 2006.

[6] Mohamed Moussa, Janaka Y. Ruwanpura and George Jergeas, "Decision Tree Module Within Decision Support Simulation System”, 2004.

[7] Marakas, G. M, "Decision support systems in the 21st century", Upper Saddle River, NJ, Prentice Hall, 2003.

[8] Marek J. Druzdzel and Roger R. Flynn, "Decision Support Systems", University of Pittsburgh, 2002.

[9] Schuyler, J., "Risk and decision analysis in projects", 2nd ed., Project Management Institute, 2001, pp. $41-74$.

[10] Hanish C. Bahl and Raymond G. Hunt, "Decision-Making Theory and DSS Design".

[11] Robert H. Bonczek, NasirGhiaseddin, Clyde W. Holsapple and Andrew B. Whinston, "The DSS development system".

[12] AlexandreGachet and Ralph Sprague, "Context in Decision Support Systems Development", University of Hawaii at Manoa, USA.

[13] Steven Salzberg, Arthur L. Delcher, Kenneth H. Fasman and John Henderson, "A Decision Tree System for Finding Genes in DNA", 1998.

[14] Steven Salzberg, "Locating Protein Coding Regions in Human DNA using a Decision Tree Algorithm", 1995.

[15] Claire Cardie, "Using Decision Trees to Improve Case-Based Learning', 1993.

[16] Saxena, K. B. C., "DSS Development Methodologies: A Comparative Review", 25th Annual Hawaii International Conference on System Sciences (HICSS'92), Los Alamitos, CA, IEEE Computer Society Press, 1992

[17] Arinze, B. "A Contigency Model of DSS Development Methodology", Journal of management Information Systems 8, 1991.

[18] Mock, T. J., "Decision tree approach to the methodological decision process." Accounting Review, Vol. 47, No. 4. , 1972, pp. 826. 


\title{
استخدام نهج شجرة القرارات لاعم اتخاذ قرار إيقاف المصانع للشركات متعددة المصانع فى حالة التوقف نتيجة قصور الطاقة
}

مثال تطبيقى : شركة لتصنيع الحديد و الصلب

\author{
محمد سعبد عيسى عثمان حسين \\ شركة العز الدخيلة للحديد والصلب، الإسكندرية، مصر
}

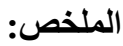

يقدم هذا البحث نهج جديد لتصميم و هيكلة نظام دعم اتخاذ قر ار لمساعدة الإدارة العليا للثركات متعددة المصانع في إتخاذ أنسب قرار لاختيار أى مصنع أو أية مصانع سيتم إيقافها نتيجة لقصور الطاقة المستخدمة. وذلك بأقل خسارة ممكنة و بأقل تأثير على الكفاءة الاتتاجية. وذللك فى ظل أزمة الطاقة التى تمر بها مصر حالياً. كما يتناول البحث أيضاً دراسة فنية لشركة كبرى لانتاج الحديد و الصلب كمثال تطبيقى لإثبات مدى امكانية تطبيق هذا النهج المقترح عملياً. 